\title{
New toolkit lets dentists build on antibiotic prescribing success
}

As new statistics reveal a fall in prescribing of antibiotics by clinicians across all NHS healthcare settings, dentists' leaders have called on colleagues to build on this success by using a new toolkit to support effective antimicrobial stewardship.

The toolkit, which includes an easy self-audit tool and patient-facing posters and leaflets, was developed as a collaboration between the Faculty of General Dental Practice UK (FGDP [UK]), the British Dental Association (BDA) and Public Health England (PHE), and builds on pioneering work from NHS Cheshire and Merseyside Local Dental Network.

With the number of people dying annually from antibiotic-resistant infections predicted to rise to 10 million by 2050 , resistance to antibiotics represents one of the biggest threats to global health. Dentists issue around $9 \%$ of all antibiotic prescriptions in NHS primary care, and $5 \%$ of the NHS total, and since 2015, healthcare providers have had a statutory duty to ensure appropriate antimicrobial use to reduce the risk of antimicrobial resistance.

However, the latest report from PHE's English Surveillance Programme for Antimicrobial Utilisation and Resistance (ESPAUR) shows that despite progress on prescribing, antibiotic resistance in the UK is still on the rise.

The free toolkit is now available to download from both the FGDP and BDA websites: http://www.fgdp.org.uk/publications/ antibiotic-stewardship.ashx

https://www.bda.org/dentists/advice/ Pages/Antibiotic-prescribing.aspx

\section{BDA AGMs}

The Annual General Meeting of the Middlesex and Hertfordshire Branch of the British Dental Association will be held at $7 \mathrm{pm}$ on Thursday, 9 February 2017 at the Holiday Inn, Elstree, WD6 5PU. M25 Junction 23. Prompt start. All members of the Branch are welcome to attend and vote. Apologies on 01992460467 or 01707 332924/394613.

\section{News in brief}

\section{New head and neck cancer guideline}

A new national clinical guideline, 'Predicting and managing oral and dental complications of surgical and non-surgical treatment for head and neck cancer', has been published with the support and approval of RD-UK (The Association of Consultants and Specialists in Restorative Dentistry), ENT UK, The British Association of Oral and Maxillofacial Surgery, The British Association of Head and Neck Oncology, The British Association of Head and Neck Oncology Nurses, The Royal College of Speech and Language Therapists and the British Dietetic Association. The guideline is available at www.restdent.org.uk/uploads/RD-UK\%20 H\%20and\%20N\%20guideline.pdf.

\section{New implant training standards}

The Faculty of General Dental Practice (UK) has published a new edition of its 'Training standards for implant dentistry', the first new edition since 2012. The document aims to provide a summary of the training that a reasonable dental practitioner carrying out safe implant dentistry in the UK should undertake, before embarking upon patient care in this discipline. The standards document can be found at: http://www.fgdp. org.uk/_assets/pdf/implant\%20training\%20 standards/fgdp $\% 20$ implant $\% 20$ training $\% 20$ standards\%202016.pdf.

\section{APPG Christmas reception}

The Christmas reception of the All-Party Parliamentary Group (APPG) for Dentistry and Oral Health took place on Tuesday 29 November in the House of Commons. Organised by the BDA who act as the Group's Secretariat, the event promoted good oral health and the celebration of Christmas in a way that won't do damage to teeth.

\section{Honours, awards, appointments}

\section{BSAD President}

The British Society for Advanced Dentistry (BSAD) announced the appointment of a new President, Dr Peter Sanders, at the recent BSAD conference in Cardiff. The BSAD, formerly known as the British Society for General Dental Surgery (BSGDS), was formed in 1983 and reformed in 2015, when the society merged with the Implant Diploma (FGDP) Alumni. Dr Sanders, who is Programme Director for the Implant Diploma FGDP at the Royal College of Surgeons, London, begins a two-year term of office from 2016-2018. http://www.bsad.website/

\section{IADR Vice President}

Members of the International Association for Dental Research (IADR) have elected Paula Moynihan, Professor of Nutrition and Oral Health at Newcastle University, as the next IADR vice president. Professor Moynihan's term will start at the conclusion of the 95th IADR General Session in San Francisco in March 2017. After serving as vice president, Professor Moynihan will stay on the IADR Board of Directors for three consecutive terms as president-elect, president and immediate past president. 